\title{
Attitudes of Special Education teachers towards sexual education of students with intellectual disabilities: Effects of religiosity and professional experiences
}

Cristina Emilia Ionescu, Alina Simona Rusu \& Carmen Costea-Bărluțiu 


\title{
Attitudes of Special Education teachers towards sexual education of students with intellectual disabilities: Effects of religiosity and professional experiences
}

\author{
Cristina Emilia Ionescu ${ }^{\text {a* }}$, Alina Simona Rusu ${ }^{a}$ \& Carmen Costea-Bărluțiu ${ }^{\text {a }}$ \\ ${ }^{a}$ Department of Special Education, Faculty of Psychology and Educational Sciences, Babess-Bolyai University, 7 Sindicatelor Street, Cluj-Napoca, \\ 400029, Romania
}

*Corresponding author: ionescu.cristina2205@yahoo.com

\section{Abstract}

Keywords:

sexual education, intellectual disability, attitudes towards sexual education, teachers' attitudes, level of religiosity.
Sexual Education (SexEd) in general is a controversial topic throughout the world. When it comes to sexual education of people with disabilities, the subject becomes even more difficult and sensitive for both caregivers and specialists. In order to implement a SexEd program for persons with intellectual disabilities, different individual and social factors should be considered. Among these factors, attitudes towards the sexuality and sexual education of those who provide it was identified as priority. In this respect, the aim of this study was to identify special educational teachers' attitudes towards teaching sex education in classroom, as well as to establish possible correlations between the attitudes towards teaching, teachers' knowledge and the way they communicate with their students about sexuality. The correlations between the general attitudes of the teachers, the attitudes towards teaching SexEd and the socio-demographic characteristics of the respondents (gender, age, parental status, professional experience, the self-declared degree of religiosity) were discussed. Interaction effects were identified and analyzed.

\section{Schlüsselworte:}

Sexualaufklärung,

Sexualkunde,

Sexualbildung, geistige

Behinderung,

Einstellungen zur

Sexualerziehung,

Einstellungen der Lehrer
Sexuale Aufklärung ist allgemein auf der ganzen Welt noch ein sehr kontroverses Thema. Besonders die sexuale Aufklärung von Menschen mit Behinderung ist ein sensibles Thema und fällt Pflegekräften sowie Fachkräften nicht leicht. Um ein Programm zur sexuellen Bildung von Menschen mit geistiger Behinderung durchführen zu können, müssen verschiedene individuelle und soziale Faktoren berücksichtigt werden. Unter all diesen Faktoren, spielen die Einstellung der Leiter solcher Programme zu Sexualität und deren sexualen Bildung, eine wichtige Rolle. Daher waren die Ziele dieser Studie spezielle Einstellungen von sonderpädagogischen Lehrern zu dem Sexualkunde Unterricht im Klassenzimmer zu ermitteln und einen Zusammenhang zwischen der Einstellung der Lehrer zum Unterrichten, dem Wissen der Lehrer und der Art wie sie mit den Schülern über Sexualität sprechen. Die Zusammenhänge zwischen der generellen Haltung von Lehrern, der Einstellung zum Unterrichten von Sexualkunde und der sozial demographische Merkmale der Befragten (wie zum Beispiel Geschlecht, Alter, Status der Eltern, Berufserfahrung, selbst ernannter Grad der Gläubigkeit) wurden diskutiert. Dabei wurden Interaktionseffekte festgestellt und analysiert.

\section{Introduction}

Sexual education (SexEd) represents an important and highly controversial topic throughout the world. The specialized literature suggests that, when it comes to the sexuality of persons with disabilities, SexEd often becomes a more difficult and delicate subject (Stinson et al., 2002). A number of factors have been identified as having an impact in developing and implementing SexEd programs for persons with disabilities of different age categories, including children. Some of the factors refer to the particularities of the beneficiaries, while others relate to the providers of these programs, often the specialists and teachers, and/or to the parents and caregivers. Examples of these factors related to the persons with disabilities (i.e. the beneficiaries of the SexEd programs) are: the degree of disability, the abilities and the limits of each person, their emotions, thoughts and feelings (Stinson et al., 2002).

Regarding the providers of these programs, a factor of major importance in the implementation of the SexEd programs for persons with disabilities refers to their attitudes towards the subject of sexuality and disability (McGuire \& Bayley, 2011). Since literature indicates that information on this delicate subject tend to be perceived differently by each person (according to their own beliefs and experiences), the attitude that these people have towards the subject might impact the way in which the information is transmitted, namely a high level of 
subjectivity might be introduced in some cases (Brown \& Pirtle, 2008). It is therefore important that those who conduct SexEd programs for persons with disabilities acknowledge their own skills, beliefs, attitudes and limitations towards the topic, in order to ensure the transmission of accurate and objective information (McGuire \& Bayley, 2011).

It is commonly acknowledged in the international literature that, in the implementation of SexEd programs, the attitudes of specialists towards sexuality and the way of teaching sexual health topics for people with disabilities might represent a crucial factor related to the effectiveness of these programs (Cohen, Sears, Byers, \& Weaver, 2004; Mkumbo, 2012). Also, it is important to take into account the fact that for those children and young people with disabilities that are spending the majority of their time in special education institutions their in-service teachers are sometimes the most accessible source of information about sexuality. Therefore, identifying teachers' general attitudes towards sexuality, as well as their attitudes towards teaching sexual education in special school, is considered an optimal starting point for the implementation of intervention programs in the field of sexual health education for people with disabilities, as well as providing appropriate training the specialists to provide an objective and accurate sex education to those in need (GonzalezAcquaro \& College, 2009).

Beyond the attitudes towards sexual education, several international studies indicate an increasing reluctance of teachers regarding the issue of teaching sexual education to children with intellectual disabilities, under the argument that those responsible for the sexual education of this category of persons should be the caregivers and/or their parents. In a study by Povilaitienè \& Radzevičienè (2013), the authors found that most teachers have a negative attitude on the idea that persons with mild cognitive disabilities can form their own families. In the same study, it was emphasized that teachers identified the parents or family of the persons with disabilities as those responsible to teach them about relationships.

Attitudes of special education teachers towards the sexual education of persons with disabilities

In recent years, person-centered ideologies have affirmed the right of the persons with disabilities to form intimate relationships. However, people with intellectual disabilities continue to face negative attitudes and restrictions in terms of opportunities for sexual expression (McGuire \& Bayley, 2011). As people with disabilities spend their entire lives in various social systems (family, community, school, work), understanding the rules that could influence the development of sexual identity is an important topic.

Various studies have been conducted on the knowledge, attitudes and concerns of caregivers, parents and teachers of people with disabilities related to sexuality, the results highlighting the need for specialist support in understanding complex issues that connect to it (Isler, 2009). The persons responsible for the inclusive education of the persons with intellectual disabilities are considered to be those who "...ensure the acquisition of social skills for integration into society, the exploration of sexuality and the awareness of ways to protect against sexual abusers or to counteract sexually transmitted diseases" (Swango-Wilson, 2008 apud Bartoş \& Rusu, 2011). The discomfort that teachers sometimes experience in teaching subjects of sexual education to children with intellectual disabilities may impact the children's education. Thus, the discovery of their own sexuality in absence of any guidance on this issue by significant adults might increase the risk of abusive relationships, sexually transmitted diseases, even unwanted pregnancy. Both emotional problems developed by children and the lack of information about sexuality were identified as possible causes for the occurrence of these risks (Boehning, 2006).

Sexual education for children with disabilities is often considered different from those for typically developed children, as most of the times they are mistakenly seen as asexual, uninterested in sex or unable to take part in sexual activities or even as "monsters" incapable of controlling their sexual impulses. These myths and preconceptions have been identified among members of the population (Anderson \& Kitchin, 2000). As sexual education is a controversial subject in many schools, especially in those accommodating children with disabilities, the type of sexual education programs, the components of the curriculum, as well as the nature of topics to be provided are often left to the schools' decision. Therefore, these programs often include total abstinence, abstinence until marriage, fear-induced planning, at the parents' request, in order for the information received at home to be strengthened by the school (SIECUS, 2001). 
The professionals' level of knowledge about sexual education can have a positive influence on the education and support provided to children with intellectual disabilities. However, teachers might not always possess the appropriate level of knowledge, mostly due to the lack of training programs. Literature indicates that teachers often report that they are poorly trained in teaching sexual education programs, and thus unable to answer the questions raised in class (Rodriguez, Young, Renfro, Ascencio, Haffner, 1996; Howard-Barr, Rienzo, Pigg \& James, 2005). In a research conducted on a group of teachers from Tanzania, it was found that positive attitudes towards teaching sexual education in schools was not enough and that it was necessary to provide teachers with knowledge, skills and confidence in teaching subjects of sexual education (Mkumbo, 2012). In another study on 68 teachers, Gonzalez-Acquaro \& College (2009), showed that providing information on sexual education and intellectual disability to teachers increases not only the level of knowledge, but also the attitudes and feelings of self-efficacy. Thus, awarenessraising and knowledge enrichment programs are necessary in the field of sexual education. Also, the increase of the level of comfort of teachers on topics such as sexuality of people with disabilities is also a condition for the efficacy of these programs (Howard-Barr, Rienzo, Pigg \& James, 2005).

Hosseinkhanzadeh (2012) focused on the attitudes of parents and teachers from Iran in relation to the sexual education of people with intellectual disabilities. It was found that about half of the participants do not agree with masturbation in the case of people with disabilities, and more than $50 \%$ agree with the use of medication to inhibit their sexual behaviors. However, $64 \%$ of teachers agreed that sexual education should be mandatory. A percent of $68 \%$ of the teachers agreed that people with disabilities have the right to form their own families, but only after attending several genetic counseling sessions, that should be mandatory for people with intellectual disabilities. In addition, both parents and teachers agreed that people with disabilities should participate in educational programs that teach them about the meaning and responsibilities of family life before they establish their own family (Hosseinkhanzadeh, 2012).

In a descriptive study on 451 teachers, Maia and colleagues (2015) investigated the teachers' opinion on sexuality and sexual education of students with intellectual disabilities. It was found that $94 \%$ of teachers were aware of their students' sexuality, 37.5\% having positive and $53.8 \%$ negative feelings regarding the issue. Even though $87.8 \%$ of teachers believed that they can contribute to the sexual education of disabled students, they considered it was necessary to prepare for the activities either on their own (39.9\%) or with school and family support $(24.4 \%)$. So even if a part of them are ready for discussion and think that the dialogue with the students is necessary, most of them feel pressured and say they have difficulties approaching the topics of sexuality with students with intellectual disabilities. Even though teachers acknowledge the need for sexual education, most of them report difficulties in teaching it, either because they lack the appropriate academic and personal training, or because they are anxious about the reactions that pupils' families might have (Maia et al., 2015).

Brown and Pirtle (2008) highlighted that the way sexuality is expressed and perceived is determined by several factors, such as culture, religion, socio-economic status and ethnic history. However, it is considered that more research is needed on these factors, as well as their impact on sexuality and intellectual disability. Religiosity, namely, the level of faith, as well as the degree of religious practice represents another category of factors that can determine how teachers and the rest of the professionals relate to sexuality issues. Berger et al. (2004) identified that teachers with a high level of faith in God disagree with gender equality, homosexuality rights, abortion or contraceptive methods as well as with the teaching of the social component of sexual education before the age of 15 .

In the light of the current research, sexual education is considered an important component that contributes to the harmonious development of persons with intellectual disabilities. Therefore, the teachers' opinions and attitudes on the issue are important to investigate, as they are considered mediators in transmitting and consolidating the information that the students are exposed to, so that they can eventually have a healthy sex life. Following a review of the previous studies, one can conclude that the attitudes of the teaching staff towards the sexual education of persons with disabilities is generally favorable, despite some negative aspects related to the topic. However, the need to develop general and research-informed knowledge about sexuality was found to be necessary among teachers, and it can lead to greater openness from their part to discuss with students about this subject. 
To our knowledge, in Romania, at national level, no previous research was conducted on investigating the attitudes of special education teachers towards the teaching of sexual education to children with intellectual disabilities. The current paper seeks to identify the attitudes towards sexuality of teachers from a special education secondary school in Romania, as well as to identify the demographic factors that might influence teachers' attitudes towards teaching of sexual health topics to children with intellectual disabilities. The main objectives of the current study are:

1. To identify the level of training (in terms of sexual health education) of special secondary school teachers in teaching sexual education in the classroom.

2. To investigate the attitudes of special secondary school teachers towards sexuality in general and their attitudes towards teaching sex education in class.

3. To analyze the correlations and moderation effects between the levels of training, professional experience, and the degree of self-reported religiosity of teachers and their attitude towards teaching sexual health education to students with intellectual disabilities.

\section{Research methodology}

\subsection{Participants}

A number of 65 teachers were selected from the Special Secondary School from Baia Mare, based on their willingness to participate voluntarily in our research (i.e., convenience sampling). The participants were aged between 23 and 65 years, with a mean age of $39.13 \pm 9.67$. In terms of gender distribution, the sample included 59 female and 6 male teachers. All the participants were residents of Baia Mare city, Maramureş county, Romania. The teachers included in the study were graduates of special education programs, psychology or had other specialties (primary and pre-primary education, social psychology, physical therapy, social assistance, mathematics, physics, law, economics, etc.), with experience between 1 year and over 20 years in the field of special education. The demographic characteristics, including the parental status of the participants, are presented in table no. 1. The level of self-reported religiosity, which was assessed with a 5-point Likert scale item ("Do you consider yourself a religious person?"), is also presented in the table no.1.
Table no. 1. Demographic characteristics of the sample

\begin{tabular}{|c|c|c|}
\hline & \multicolumn{2}{|c|}{ Participants } \\
\hline Gender & $\begin{array}{l}\text { female }(\%) \\
\text { male }(\%)\end{array}$ & $\begin{array}{l}90.8 \% \\
9.2 \%\end{array}$ \\
\hline Age & $\begin{array}{l}\text { Minimum (years) } \\
\text { Maximum (years) } \\
\text { Mean (SD) }\end{array}$ & $\begin{array}{l}23 \\
65 \\
39.13(9.67)\end{array}$ \\
\hline Parental status & $\begin{array}{l}\text { No kids }(\%) \\
\text { With kids }(\%)\end{array}$ & $\begin{array}{l}35.4 \% \\
64.6 \%\end{array}$ \\
\hline Studies & $\begin{array}{l}\text { Psychology, special } \\
\text { education }(\%) \\
\text { Other specialties } \\
(\%)\end{array}$ & $\begin{array}{l}72.3 \% \\
27.7 \%\end{array}$ \\
\hline $\begin{array}{l}\text { Experience in } \\
\text { special school }\end{array}$ & $\begin{array}{l}\text { Less than } 10 \text { years } \\
(\%) \\
\text { More than } 10 \text { years } \\
(\%)\end{array}$ & $\begin{array}{l}63.1 \% \\
36.9 \%\end{array}$ \\
\hline $\begin{array}{l}\text { Self-reported level } \\
\text { of religiosity }\end{array}$ & $\begin{array}{l}\text { High }(\%) \\
\text { Medium (\%) } \\
\text { Low }(\%)\end{array}$ & $\begin{array}{l}32.3 \% \\
49.2 \% \\
18.5 \%\end{array}$ \\
\hline
\end{tabular}

\subsection{Instruments}

Two questionnaires that were developed and used in other studies were selected for the study in order to identify the types of attitudes and the level of SexEd knowledge of teachers from the special school. The instruments have been translated and adapted for Romanian language usage by the authors of the study.

1. The Attitudes toward Sexuality Scale, ATSS (Fisher, 1988) was included in the study in order to identify the general attitudes of teachers towards sexuality. The authors of the questionnaire have used and modified some of the items of the Calderwood Questionnaire of Attitudes about Human Sexuality (Calderwood, 1971), resulting in the Attitudes toward Sexuality Scale, that covers a large proportion of sexuality topics. The ATSS questionnaire includes 13 items targeting the attitude on different topics of sexuality such as nudity, abortion, contraception, premarital sex, pornography, prostitution, homosexuality and sexually transmitted diseases. The items are ranked on the Likert scale from 1 to 5, from total disagreement to total agreement. The results may range from 13 to 65 , with smaller scores indicating a high degree of conservatism in terms of sexuality, and higher scores indicating a high level of permissiveness for the same subject. The ATSS questionnaire' proved to have a fair internal 
consistency, as shown by the values of Alpha Cronbach that various authors reported for different categories of respondents. Thus, for a group of preadolescents aged 12-14, Alpha Cronbach coefficient was 0.76 , for adolescents aged 15-17 years its value was 0.65 , while for the 18 to 20 years old respondents, the coefficient was 0.80 (Fisher, 1988). The authors found a more adequate alpha Cronbach for an adult group, with a value of 0.84 , indicating very good internal consistency for this questionnaire, which is another reason why it was chosen for the current research.

\section{Attitudes toward Teaching Human Sexuality} Inventory, ATTHSI (Schultz \& Boyd, 1981) was designed to evaluate the attitudes of in-service teachers towards sexual education in order to help the development of the sexual education field. After a consistent analysis of the literature on sexuality, the authors selected several topics to be covered in identifying personal attitudes about sexuality and about its teaching in class. Thus, the items were divided into 5 scales: (GK) general knowledge of sexuality, (CS) communication with students, (IC) community influence, (SAPI) school administration and peer influences, (SSFSE) special school as a facilitator of sexual education. The questionnaire includes 55 items, ranked on the Likert scale from 1 to 5 , from total disagreement to total agreement. The higher scores for the first two scales, show better knowledge and communication with the pupils. For the other 3 scales, higher scores show greater openness of the community, school administration and special school as a facilitator of sexual education on this subject. Schultz and Boyd (1981), used the questionnaire in their study and reported Alpha Cronbach values as follows: for general attitudes towards the teaching of sexual education 0.87 , for the subscale of general knowledge about sexuality 0.9 , which indicated very good internal consistency, while for the subscale of community influences, the Alpha Cronbach coefficient was 0.42 , a possible explanation for this being the small number of items in this subscale. The results of the Alpha Cronbach reliability coefficients contributed to the selection of this second measure for the current research.

\subsection{Procedure}

After the translation and linguistic adaptation of the instruments into Romanian by the authors of the study, these were applied individually in paper-pen form to each of the participants. The questionnaires were given to the participants to have them at home and were returned after these were filled in.

\subsection{Results}

\section{Psychometric properties of the used questionnaires}

Table no. 2 shows that for both the ATSS questionnaire and the ATTHSI questionnaire, the Alpha Cronbach coefficient we obtained for the sample of this research is high, with results close to those obtained in previous studies. Therefore, both scales proved to have an appropriate internal consistency. The reliability for the 5 subscales of the ATTHSI was also investigated. The first two scales, general knowledge about sexuality (GK-20 items) and communication with students (CS-15 items) showed good internal consistency for the studied sample (table no. 2). The internal consistency of scale 4, which refers to school administration and peer influences (SAPI8 items), proved to be low. However, the scales that refer to the special school as a facilitator of sexual education (SSFSE-6 items- 4 after exclusion) and to the influence of the community (IC-6 items- 4 after exclusion), have the Cronbach alpha coefficient below the accepted value of 0.5 .

Several problematic items were decided to be removed in order to obtain more reliable coefficients. Thus, items 2 and 49 were removed because they were found to decrease the value of Alpha Cronbach and were considered irrelevant to the scale they belonged to. We consider that during the translation process from English language to Romanian, the items 8 and item 37 were formulated in a way that created some comprehensibility difficulties to the participants. It is important to mention that even after the removal of more problematic items, the values of Alpha Cronbach remained relatively low and, as a consequence, the results of this study have to be interpreted with caution. One possible explanation for the low reliability can be the small number of items in the two subscales of the ATTHSI questionnaire, as stated by Schultz and Boyd (1981). Also, characteristics of the participants, gender, age, parental status, specialty studies, special school experience and self-reported 
religiosity level could influence the value of the reliability coefficient.

Table no. 2. Values of Alpha Cronbach coefficient for the instruments and their subscales, before and after the removal of the problematic items

\begin{tabular}{|l|l|l|l|l|}
\hline Scale & \multicolumn{2}{|l|}{ Alpha Cronbach } & $\begin{array}{l}\text { Item } \\
\text { deleted }\end{array}$ & $\begin{array}{l}\text { Alpha } \\
\text { after } \\
\text { deleted } \\
\text { item }\end{array}$ \\
\hline & $\begin{array}{l}|l| \\
\text { Reported } \\
\text { by the } \\
\text { authors }\end{array}$ & $\begin{array}{l}\text { Determined } \\
\text { in the current } \\
\text { study }\end{array}$ & & \\
\hline ATSS & .84 & .816 & & \\
\hline ATTHSI & .87 & .841 & & \\
\hline GK & .90 & .875 & & \\
\hline CS & & .768 & & \\
\hline SSFSE & & .395 & $\begin{array}{l}\text { Item } 8, \\
\text { item 37 }\end{array}$ & .449 \\
\hline SAPI & .42 & .533 & & \\
\hline IC & & .268 & $\begin{array}{l}\text { Item 2, } \\
\text { item 49 }\end{array}$ & .328 \\
\hline
\end{tabular}

\section{Correlations and comparisons between variables}

A series of Pearson correlations were computed among the variables of the study. The positive correlation between ATSS and ATTHSI $(r=.309, p<0.05)$ indicates that the more favorable the general attitudes of participants about sexuality (ATSS) are, the higher is the openness to teach sexual education in special schools (ATTHSI). The analysis of the correlations between the ATSS scale and the 5 subscales of the ATTHSI questionnaire, allowed the identification of a significant positive correlation between the general score of the ATSS scale and subscale CS of the ATTHSI questionnaire $(\mathrm{r}=.471, \mathrm{p}<0.01)$, i.e., the subscale that relates to communication with students about sexuality. This means that the higher the scores for the general attitude regarding sexuality is, the greater is the teachers' willingness to communicate with their pupils about this subject.

Correlations were also computed between the overall (global) scores of the ATTHSI questionnaire and its subscales. Positive correlations were found between the overall score and those obtained in four out of the five subscales: general knowledge about sex education $(\mathrm{r}=$ $.857, \mathrm{p}<0.01)$, communication with students $(\mathrm{r}=.819, \mathrm{p}$ $<0.01$ ), school administration and peer influences $(\mathrm{r}=$ $.298, \mathrm{p}<0.05)$ and community influence $(\mathrm{r}=.490, \mathrm{p}$ $<0.01$ ). In addition, positive and inter-scale correlations were found between: subscale GK and subscale CS ( $\mathrm{r}=$ $.585, \mathrm{p}<0.01$ ), meaning that a better knowledge of sex education topics is related to better communication with students about this subject; between subscale IC and subscale GK $(\mathrm{r}=.316, \mathrm{p}<0.05)$ and subscale CS $(\mathrm{r}=.256$, $\mathrm{p}<0.05$ ), meaning that the influence of the community is an important factor in knowing and communicating with the students about sexual education.

Table no. 3. Values of the inter-scales Pearson correlations

\begin{tabular}{|l|l|l|l|l|}
\hline & ATSS & ATTHSI & GK & CS \\
\hline 1. ATSS & & & & \\
\hline 2. ATTHSI & $.309^{*}$ & & & \\
\hline 3. GK & & $.857^{* *}$ & & \\
\hline 4. CS & $.471^{* *}$ & $.819^{* *}$ & $.585^{* *}$ & \\
\hline 5. SAPI & & $.298^{*}$ & & \\
\hline 6. IC & & $.490^{*}$ & $.316^{*}$ & $.256^{*}$ \\
\hline \\
orrelation is significant at the 0.01 level (2-tailed) \\
rolation is significant at the 0.05 level (2-tailed)
\end{tabular}

To compare the differences between two independent samples for the demographic groups (gender, age, parental status, specialization and experience), we used Student's t-test for independent samples. As it can be observed in table no. 4 , there is a statistically significant difference in the teachers' willingness to communicate with children about sexuality, depending on their gender. After comparing the means, it was found that the male participants in our sample were more open towards communicating with children about sexuality topics than the female gender participants. For the same group, we found a significant difference regarding the influence of school administration and peer influence. Thus, the male participants in our group appeared to be less influenced by the school administration than the female gender group.

Taking into consideration the age group, it was noticed a significant difference between the categories of participants with the age lower than 40 and the ones over 40 regarding the general attitudes towards sexuality, the first group being more open towards sexuality subjects. A similar result was observed when we compared the means of the participants with no children with the ones that have their own children. Thus, the participants with children tended to have more conservatist attitudes towards sexuality. Also, there was a mean difference between the ones without children when it came to communication with students meaning that the communication with students tends to be more facile for the teachers without children.

A difference was also acknowledged in our sample referring to specialization in relation with the school 
administration and peer influence. By comparing the means, it was observed that the persons specialized in social studies were more influenced by the school administration and peers than the ones that are specialized in other fields.

Another difference was noticed between the participants with less than 10 years of experience in special education and the ones with more than 10 years of experience regarding their general attitudes towards sexuality, meaning that the more experienced participants tended to have a higher degree of conservatism towards sexuality.
An ONEWAY-ANOVA test was used to determine the significance of the differences regarding sexuality and sex education depending on the participants self-reported level of religiosity. A significant difference was found between the groups regarding the general attitudes towards sexuality $(\mathrm{p}<.001)$, the attitudes towards teaching human sexuality $(\mathrm{p}<.005)$ and, also the scale regarding communication with children $(\mathrm{p}<.001)$. As the selfdeclared level of religiosity of the teachers was higher, their general attitudes about sexuality issues tended to be more conservative, the openness to teach sex education topics in the special school more limited and the communication with students about sex topics more problematic.

Table no. 4. Means and standard deviations of the scores to different scales and subscales, depending on the demographic

\begin{tabular}{|c|c|c|c|c|c|c|c|c|}
\hline & & & & $M$ & $(S D)$ & & & \\
\hline \multirow{4}{*}{ Gender } & & ATSS & ATTHSI & GK & $\mathrm{CS}$ & SSFSE & SAPI & IC \\
\hline & Feminine & 42.81 & 178.03 & 82.55 & 48.38 & 11.10 & 20.77 & 11.77 \\
\hline & & $(8.98)$ & (18.86) & (11.06) & $(8.37)$ & (3.12) & $(4.30)$ & (2.53) \\
\hline & Masculine & 44.50 & 192.50 & 84.66 & 56.83 & 12.33 & 23.50 & 11.66 \\
\hline \multirow{4}{*}{ Age } & Less than 40 & $\begin{array}{l}(15.46) \\
45.42\end{array}$ & $\begin{array}{l}(19.37) \\
178.42\end{array}$ & $\begin{array}{l}(13.89) \\
80.96\end{array}$ & $\begin{array}{l}(7.33)^{* *} \\
50.54\end{array}$ & $\begin{array}{l}(2.50) \\
1148\end{array}$ & $\begin{array}{l}(2.88)^{*} \\
20.45\end{array}$ & $\begin{array}{l}(3.38) \\
1175\end{array}$ \\
\hline & & $(10.38)^{* *}$ & (18.33) & $(10.13)$ & (8.98) & $\begin{array}{l}11.40 \\
(3.08)\end{array}$ & $(4.21)$ & $(2.47)$ \\
\hline & More than 40 & 40.43 & 180.34 & 84.59 & 47.75 & 10.33 & 21.62 & 11.78 \\
\hline & & (8.10) & (20.35) & (12.16) & $(8.04)$ & (3.09) & $(4.27)$ & $(2.74)$ \\
\hline \multirow{4}{*}{$\begin{array}{l}\text { Parental } \\
\text { Status }\end{array}$} & No kids & 46.30 & 181.65 & 82.21 & 51.65 & 11.78 & 21.34 & 11.73 \\
\hline & & $(10.01)^{* *}$ & (18.50) & $(10.45)$ & $(9.56)^{*}$ & $(2.27)$ & $(4.35)$ & (2.11) \\
\hline & With kids & 41.14 & 178.11 & 83.04 & 47.80 & 10.90 & 20.85 & 11.78 \\
\hline & & (8.96) & (19.71) & (11.76) & (7.79) & $(3.42)$ & $(4.23)$ & (2.84) \\
\hline \multirow[t]{4}{*}{ Specialization } & Social & 43.42 & 179 & 83.53 & 49.17 & 11.02 & 19.97 & 11.97 \\
\hline & studies & $(9.54)$ & (20.64) & (12.26) & (9.18) & $(3.43)$ & (4.16) & $(2.77)$ \\
\hline & Others & 41.77 & 180.33 & 80.72 & 49.16 & 11.72 & 23.77 & 11.22 \\
\hline & & $(9.54)$ & $(15.37)$ & $(7.92)$ & $(7.04)$ & $(1.84)$ & $(3.15)^{* *}$ & $(2.01)$ \\
\hline \multirow[t]{4}{*}{ Experience } & Less than 10 & 44.68 & 179.85 & 82.14 & 50.26 & 11.21 & 20.92 & 11.97 \\
\hline & years & $(10.15)^{*}$ & (18.05) & (10.28) & (9.18) & (3.03) & $(4.40)$ & (2.59) \\
\hline & More than 10 & 40.04 & 178.54 & 83.79 & 47.29 & 11.20 & 21.20 & 11.41 \\
\hline & years & $(7.92)$ & (21.45) & (12.87) & $(7.25)$ & (3.21) & $(4.05)$ & (2.06) \\
\hline \multirow{6}{*}{$\begin{array}{l}\text { Self-declared level } \\
\text { of religiosity }\end{array}$} & Low & 54.58 & 194.08 & 87.41 & 58 & 12.33 & 21.41 & 12.08 \\
\hline & & $(5.40)^{* *}$ & $(18.02)^{*}$ & (11.79) & $(8.50)^{* *}$ & $(2.22)$ & $(5.01)$ & (3.05) \\
\hline & Medium & 42.75 & 176.71 & 82.83 & 46.78 & 11.37 & 20.28 & 12.03 \\
\hline & & (7.65) & (18.02) & (10.72) & (7.27) & $(3.25)$ & $(4.30)$ & (2.07) \\
\hline & High & 36.66 & 175 & 79.80 & 47.76 & 10.33 & 21.95 & 11.19 \\
\hline & & $(8.07)$ & $(18.41)$ & (11.28) & (7.49) & (3.10) & $(3.65)$ & (3.02) \\
\hline
\end{tabular}

\section{Moderation analysis}

To explore whether the level of self-reported religiosity has an effect on the association between the general attitude toward sexuality and the teachers' communication about sex education themes, a moderation analysis was conducted, using Process Macro for SPSS. The level of religiosity and general attitude toward sexuality accounted for a significant amount of the variance in the communication about sex education themes: $\mathrm{R}^{2}=.29, \mathrm{~F}(3,61)=9.91, \mathrm{p}<.001$. After adding the interaction term, a significant proportion of the variance in communication was found, $\Delta \mathrm{R}^{2}=.06, \Delta \mathrm{F}(1$, $61)=6.41, \mathrm{p}=.01, \mathrm{~b}=-.33, \mathrm{t}(61)=-2.53, \mathrm{p}=.01$. From the examination of the interaction plot (figure no. 1), a diminishing effect of religiosity level was noticed, meaning that as the level of religiosity increased, the effect of general attitudes on the communication about sexuality with students decreased. At low attitudes, the communication was more probable for those with higher level of religiosity, while those with low level of religiosity tended to have low levels of communication 
with students about sexuality. As the general attitudes became more positive, those with higher levels of religiosity tended to remain constant in their willingness to communicate, while the teachers with lower levels of religiosity had high willingness to communicate about sexuality with students. The teachers with low selfdeclared level of religiosity, who had positive general attitudes about sexuality had the highest level of willingness to communicate with students about sex education themes.

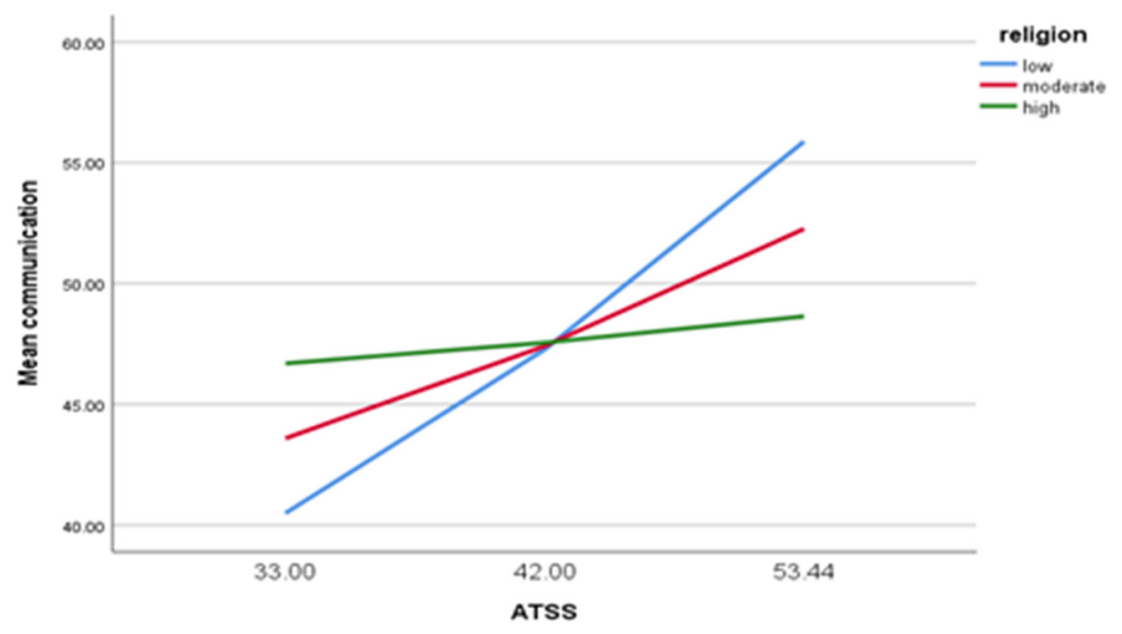

Figure no. 1. The interaction effect of religiosity on the attitudes toward sexuality and communication of SexEd topics with the students.

An interaction model was constructed in order to explore whether the level of experience in teaching (under and above 10 years) has an effect on the association between the general attitude toward sexuality and the teachers' communication about SexEd topics. The experience level and the general attitude toward sexuality accounted for a significant amount of the variance in the communication about sex education themes: $\mathrm{R}^{2}=.36$, $\mathrm{F}(3,61)=16.55, \mathrm{p}<.001$. After adding the interaction term, a significant proportion of the variance in communication was found, $\Delta \mathrm{R}^{2}=.14, \Delta \mathrm{F}(1,61)=26.76$, $\mathrm{p}<.001, \mathrm{~b}=.15, \mathrm{t}(61)=-5.17, \mathrm{p}<.001$, proving the significance of the interaction effect. The examination of the interaction plot revealed a diminishing effect of the level of experience, meaning that higher levels of experience in teaching (above 10 years) accounted for lower level of willingness to talk about sexuality with students, despite more positive attitude toward sexuality in general. Teachers with more negative attitudes tended to exhibit more willingness to talk about sexuality when they had higher experience in teaching. The communication was more probable for those with more experience and a positive attitude about sexuality in general.

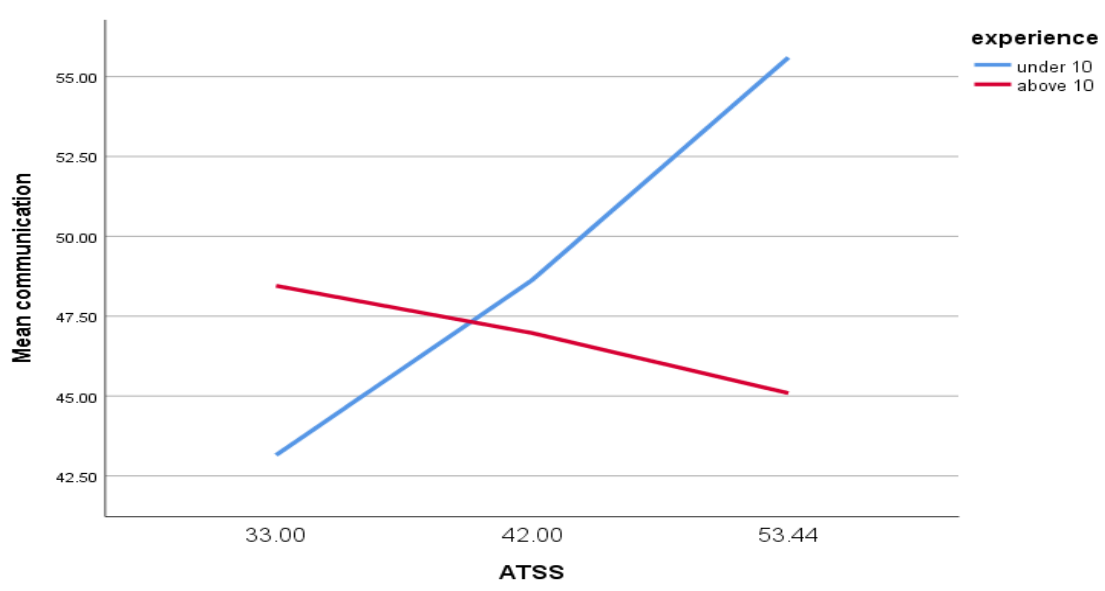

Figure no. 2. The interaction effect of experience on the attitudes toward sexuality and communication of SexEd topics with the students 


\section{Discussions}

Our research investigated the correlates of the teachers' attitudes toward teaching sex education topics in special schools. We found that the general attitudes towards sexuality were significantly related to the teachers' attitudes towards teaching sexual education. In terms of age, the older participants proved to be more conservative, as well as those who had their own children.

The most significant negative correlation was found between the self-declared degree of religiosity of the participants and their general attitudes towards sexuality issues. Thus, the more religious the participants considered themselves to be, the more conservative they tended to be when approaching sexuality. The analysis of the results shows that teaching sexual education topics in special schools is more limited as the self-perceived level of religiosity is higher. In addition, if the respondents reported to be more religious, the openness for knowledge, the communication with students about sexuality issues, and their tendency to see the special school as a facilitator in the sexual education of children were more limited compared to those who perceived themselves as less religious. A significant interaction effect of the level of religiosity and the professional experience of the participants was found regarding the impact of the general attitudes about sexuality on the willingness to communicate with students about sex education topics. The participants that assessed their level of religiosity as high, tended to maintain a more conservative attitude towards teaching sex education topics, while those that assessed their level of religiosity as low exhibited a tendency to speak about sex education and their general attitude about sexuality was more positive.

The implication that we can derive would be that religiosity should be an important factor that needs to be taken into consideration when designing sex education training programs for teachers. Also, the development of a more positive attitude towards sexuality should not be the main objective of such programs, as for some teachers (in our study, those with higher religiosity), it did not account for an increase of the openness to communicate with students. Other factors need further investigation in order to improve the teachers' openness to talk about sex education topics.
Our findings indicate that the professional experience should be taken into account when designing SexEd teacher training programs, as it could be a relevant factor in the openness towards sexuality education. In our investigation, teachers with more years of experience were less open to talk about sex education even if they had a positive attitude about sexuality, while those with less than 10 years of experience were more opened as their general attitude toward sexuality was more positive. We conclude that for less experienced teachers (in terms of the length of their presence in special education institutions), more information about sexuality could be useful in order to increase their openness to talk with students, while those with more experience need other types of trainings in order to improve their willingness to teach sex education.

\section{Limits}

Consideration should be given to the low number of participants, especially male ones. In addition, our study was carried out only at the level of a single institution of special education in the country, so careful consideration should be given to the generalizability of our conclusions. Another limit of research is represented by the self-report measures used, in terms that it is necessary to consider the social desirability of the responses that the participants may give in completing the questionnaires. Providing control items or a scale on the level of social desirability could be a possible solution to implement in other investigations.

\section{Future directions}

A possible new research direction would be to include, by using a randomized sampling method, a larger number of participants from various special education institutions in the country, as well as pre-service teachers. At the same time, based on the results we obtained, intervention and training programs for teachers in the field of Special Education can be further developed to increase their knowledge of sexual education and help them facilitate the communication with students with moderate intellectual disabilities about sexuality issues, as well as with their tutors and/or parents. Another research direction refers to the qualitative analysis of the needs and difficulties faced by special education teachers, as well as their knowledge of the current ethical and legislative 
frames, in order to prepare training programs or interventions in the field of sexual health education.

\section{Authors note:}

Cristina E. Ionescu (special educator) has obtained her master's degree in special education at the Faculty of Psychology and Educational Sciences, Babeș-Bolyai University of Cluj-Napoca, Romania. Her professional and research interests are: intellectual disability, digital storytelling, social difficulties in disability and sexual education.

Carmen Costea-Bărluțiu (special educator and psychotherapist) is currently a Lecturer in the Department of Special Education, Faculty of Psychology and Educational Sciences, Babeș-Bolyai University of ClujNapoca, Romania and a systemic couple and family psychotherapist in private practice. Her interests and training in psychotherapy include: Ericksonian Hypnotherapy, Schema-focused therapy, Mentalizationbased treatment, Attachment-based interventions. She has professional and research interests in: attachment theory in human development and psychotherapy, parenting and disability, systemic psychotherapy and family well-being.

Alina S. Rusu (biologist and psychologist) is currently an Associate Professor in the Department of Special Education, Faculty of Psychology and Educational Sciences, Babes-Bolyai University of Cluj-Napoca, Romania and member of the Doctoral School "Education, Reflection, Development" (domain: Psychology). Her professional and research interests are: human education, interdisciplinary curriculum development, applied values of human-animal interactions and the multidimensional study of community-oriented volunteering. She teaches courses in animal psychology, psychobiology of human sexuality, and positive psychology applied to inclusive institutions.

\section{References}

Anderson, P., Kitchin, R. (2000). Disability, space and sexuality: access to family planning services. Social Science $\&$ Medicine, 51, 59-66.

Bartoș, S., Rusu, A. (2011). Psihobiologia sexualității. Idei de cercetare [Psyhobiology of sexuality. Research ideas]. Cluj Napoca: Sinapsis.

Berger, D., Bernard, S., Carvalho, G., Munoz, F., \& Clement, P. (2007). Sex education: analysis of teachers' and future teachers' conceptions from 12 countries of Europe, Africa and Middle East.

Boehning, A. (2006). Sex Education for Students with Disabilities. Law \& Disorder, 1, 59-66.

Brown, R.D., Pirtle, T. (2008). Beliefs of professional and family caregivers about the sexuality of individuals with intellectual disabilities: examining beliefs using a Qmethodology approach. Sex Education, 8, 59-75.

Boyd, J.R. (1981). Sexuality attitudes of Iowa secondary teachers, Retrospective Theses and Dissertations. Iowa: Alma.

Cohen J.N, Sears, B., \& Weaver, A.D. (2004). Sexual health education: Attitudes, knowledge and comfort of teachers in New Brunswick schools. The Canadian Journal of Human Sexuality, 13, 1-15.

Fisher, T. (1988). Attitudes toward Sexuality Scale. Handbook of Sexuality-Related Measures, 66-67.

Gonzalez-Acquaro, K., College, W. (2009). Teacher Training, Sexuality Education, and Intellectual Disabilities: An Online Workshop. Current Issues in Education, vol. 11, no. 9.

Hosseinkhanzadeh, A.A., Taher, M., \& Esapoor, M. (2012). Attitudes to sexuality in individuals with mental retardation from perspectives of their parents and teachers. International Journal of Sociology and Anthropology, Vol. 4(4), 134-146.

Howard-Barr, E., Rienzo, B., Pigg, R., \& James, D. (2005). Teachers' beliefs, professional preparation, and practices regarding exceptional students and sex education. Journal of School Health, 75 (3), 99-104.

Isler, A., Beytut, D., Tas, F., \& Conk, Z. (2009). A study on sexuality with the parents of adolescents with intellectual disability. Sexuality and Disability, 27, 229-237.

Maia, A.C., Yamauti, V.L., Schiavo, R.A., Capellini, V.L.M., \& Valle, T.G.M. (2015). Teacher opinions on sexuality and Sexual Education of students with intellectual disability. Estudes de psicologia (Campinas), Vol.32, no.3.

McGuire, B.E., Bayley, A. A. (2011). Relationships, sexuality and decision-making capacity in people with an intellectual disability. Current Opinion in Psychiatry, 24, 398-402.

Mkumbo, K.A. (2012). Teachers' Attitudes towards and Comfort about Teaching School-Based Sexuality Education in Urban and Rural Tanzania, 4(4), 149-158.

Povilaitienè, N., Radzevičienè, L. (2013). Parents' and Teachers' Attitude to Family Planning of Adolescents with Mild Intellectual Disabilities in the Context of Conceptions of Gender and Sexuality. Social Welfare Interdisciplinary Approach, 3(2), 8-18.

Rodriguez, M., Young, R., Renfro, S., Ascencio, M., \& Haffner, D. (1996). Teaching our teachers to teach: A SIECUS study on training and preparation for HIV/AIDS Prevention and Sexuality Education, 28 (2), 1-9.

Stinson, J., Christian, L.A., \& Dodson, L.A. (2002) Overcoming barriers to the sexual expression of women with developmental disabilities. Research and Practice for Persons with Severe Disability, 27, 18-26.

Swango-Wilson, A. (2008). Caregiver Perception of Sexual Behaviors of Individuals with Intellectual Disabilities. Sexuality and Disability, 26 (2), 75-81.

*** Sexuality Education and Information Council of the United States SIECUS (2009). Questions and answers: fact sheet on sexuality education. 